\title{
Thromboelastography Profile of Patients with COVID-19 Admitted to Intensive Care Unit: A Single-center Retrospective Study from India
}

\author{
Sanjith Saseedharan ${ }^{1}$, Vijay B Talla ${ }^{2}$, Annapurna Chiluka ${ }^{3}$
}

\begin{abstract}
Coronavirus disease (COVID-19) causes thromboinflammation resulting in a high incidence of venous thromboembolism (VTE) events, which occur in significant numbers despite giving standard thromboprophylaxis with low-molecular-weight heparins. Various markers and tests have been evaluated and found to have a strong association with the worse prognosis of the disease. Common coagulation markers like D-dimer and fibrinogen give more of a static picture of coagulation, whereas viscoelastic tests like thromboelastography (TEG) provide an understanding of the coagulation function and help in better interpretation. We conducted a retrospective analysis of TEG values of 32 patients with COVID19 admitted to the intensive care unit (ICU). Hypercoagulation as defined by TEG-coagulation index (CI) higher than the upper limit of the normal reference range (NRR) is found in $62.5 \%$ of the patients. There is also a clear representation of hypercoagulability as reflected by TEG-R, TEG-K, and TEG-LY30 values lower than or toward the lower limit of NRR, and TEG-ANGLE, TEG-MA, and TEG-CI values higher than or toward the upper limit of NRR which is more pronounced in severe forms of the disease, both in comparison to NRRs and other non-COVID ICU patients. Findings are similar to that of earlier studies in patients with COVID-19 except for the LY30, which is retained in the majority of our patients. Thromboelastography can be a useful tool to understand and screen for COVID-19-related hypercoagulability and may help predict VTE events. The potential of TEG to determine the optimal anticoagulant therapy needs to be evaluated in larger prospective studies.

Keywords: Coagulation disorder, Coronavirus disease, Intensive care unit, Thromboelastography.

Indian Journal of Critical Care Medicine (2020): 10.5005/jp-journals-10071-23675
\end{abstract}

\section{INTRODUCTION}

A cluster of pneumonia cases was reported on December 31, 2019, in Wuhan, China's Hubei Province, which was eventually named as severe acute respiratory syndrome coronavirus 2 (SARS-CoV-2) as the causative agent and was declared a pandemic by World Health Organization (WHO). The number of confirmed cases as of June 29, 2020, the 6-month anniversary of the coronavirus disease (COVID19) outbreak, was over 10 million cases with around 500,000 deaths. ${ }^{1}$

Severe acute respiratory syndrome coronavirus 2 gains entry to human cells by binding to angiotensin-converting enzyme 2 (ACE-2) receptors expressed on the respiratory epithelium and other sites including endothelium. ${ }^{2}$ Uncontrolled viral replication at these sites can cause inflammation and hypercoagulability as evidenced by venous and arterial thrombosis and multiorgan dysfunction. ${ }^{3}$

In a large case series of hospitalized patients with COVID-19 from New York, $14.2 \%$ were treated in an intensive care unit (ICU), $12.2 \%$ required invasive mechanical ventilation (IMV), and $21 \%$ died. ${ }^{4} \mathrm{~A}$ recent review on thrombosis risk in COVID-19 by Al-Ani et al. reported the occurrence of venous thromboembolism (VTE) in approximately $20 \%$ of patients and with cumulative incidences up to $49 \%$ during hospitalization. ${ }^{5}$ Studies have also consistently reported a significant increase in D-dimer and high levels were associated with an increase in the risk of thrombosis, progression to critical illness, and mortality suggesting a crucial role of coagulopathy in the prognosis of the disease. ${ }^{6}$

Thromboelastography (TEG), commonly used to guide transfusion of hemostatic products, is a test of hemostasis that measures clot formation and dissolution in real-time. Thromboelastography can be a useful adjunct to clinical judgment to stratify a patient's risk of developing thromboembolism. ${ }^{7}$ We
1,3 Department of Intensive Care Unit, SL Raheja Hospital, Mumbai, Maharashtra, India

2Department of Pharmacology, Andhra Medical College, Visakhapatnam, Andhra Pradesh, India

Corresponding Author: Vijay B Talla, Department of Pharmacology, Andhra Medical College, Visakhapatnam, Andhra Pradesh, India, Phone: +91 7702107060, e-mail: drvijaybhushanam@gmail.com

How to cite this article: Saseedharan S, Talla VB, Chiluka A. Thromboelastography Profile of Patients with COVID-19 Admitted to Intensive Care Unit: A Single-center Retrospective Study from India. Indian J Crit Care Med 2020;24(12):1218-1222.

Source of support: Nil

Conflict of interest: None

carried out a retrospective analysis of TEG data of critically ill patients with COVID-19 admitted to ICU, to study the coagulation states and to understand the utility of TEG in this setting.

\section{Materials and Methods}

This study was done as a retrospective chart review of data collected for clinical purposes. Data of consecutive patients with COVID admitted to the ICU between May 22, 2020, and June 22, 2020, were studied.

As per our institutional protocols and practices, all patients were shifted to ICU only if they match moderate severity of acute respiratory distress syndrome (ARDS) Berlin definition, ${ }^{8}$ COVID severity was defined based on Indian government guidelines, ${ }^{9}$ 
all patients were already on prophylactic anticoagulation with low-molecular-weight heparin (LMWH), and were generally put on either non-rebreathing masks warranting high flow nasal cannula, non-IMV, or IMV. The clinical condition was assessed and blood for routine testing was collected on arrival to ICU. Thromboelastography, as per the hospital protocol to understand the coagulation profile better, was performed for all COVID patients admitted to ICU, within 1 hour of specimen collection using TEG $^{\circledR} 5000$ Thromboelastograph ${ }^{\circledast}$ Hemostasis Analyzer System (Haemonetics, Boston, MA, USA) with citrated kaolin in heparinase as the reagent. Quality-control checks were performed regularly according to the manufacturer's instructions.

Statistical analyses were performed using SPSS (Version 16.0; Statistical Package for Social Sciences, Chicago, IL, USA). For descriptive analyses, variables were expressed as mean values and standard deviations (SD) or frequency and percentages. Independent-samples $T$-test was used to analyze the difference between the means. Pearson correlation was used to determine the correlation between TEG parameters and other clinical data. A $p$ value of $<0.05$ was considered statistically significant.

\section{Results}

Thirty-two critically ill patients with TEG data were included in the analysis. There were no patients with known altered coagulable states like blood product transfusion within 24 hours of TEG, thrombocytopenia, liver failure, or current antiplatelet therapies. All patients were already receiving prophylactic anticoagulation with $40 \mathrm{mg}$ enoxaparin subcutaneous once daily. Patient demographics are mentioned in Table 1.

The mean values for hematological parameters and TEG values vis-à-vis the manufacturer's NRR are mentioned in Table 2. Mean fibrinogen levels are higher than the normal range with slightly higher values for INR and aPTT. All the mean TEG values are within the manufacturer's NRR, with mean TEG-MA and TEG-Cl clearly toward the upper limit of NRR, reflecting a possible hypercoagulable state.

Comparison of mean TEG values in relation to comorbidity, COVID severity, and IMV showed that the hypercoagulable nature of the disease is more pronounced in severe forms of the disease.

Fourteen patients have abnormal TEG patterns with "Combined enzymatic and platelet hypercoagulability" being the most common abnormality pattern (Table 3 ). Hypercoagulation as defined by $\mathrm{Cl}$ higher than the upper limit of NRR is found in $62.5 \%$ of the patients (Table 4).

Correlation analysis is done between severity scores-SOFA, APACHE, and the TEG parameters, and a significant positive correlation is seen between SOFA score and TEGMA (Supplementary Table 1).

\section{Discussion}

As per our knowledge, our study is the first Indian study to observe the TEG profiles in patients with COVID-19. Compared to the manufacturer's NRR values, as well as two other Indian studies in the healthy population, ${ }^{10,11}$ the TEG values in our study have shown a hypercoagulable state, reflected by TEG-R, TEG-K values lower than or toward the lower limit of NRR, and TEG-ANGLE, TEG-MA, TEG-CI values higher than or toward the upper limit of NRR. This is more pronounced in severe forms of the disease- "Comorbidity", "Severe COVID", and "IMV" groups. The findings are hypercoagulable even
Table 1: Demographics

\begin{tabular}{|c|c|}
\hline Variable $(n=32)$ & Mean $( \pm S D)$ or frequency (\%) \\
\hline Age (years) & $58.19( \pm 14.89)$ \\
\hline \multicolumn{2}{|l|}{ Sex } \\
\hline - Male & • $23(71.9 \%)$ \\
\hline - Female & - $9(28.1 \%)$ \\
\hline Days of illness & $5.28( \pm 3.45)$ \\
\hline $\begin{array}{l}\text { Days of admission to hospital } \\
\text { (post illness) }\end{array}$ & $5.63( \pm 3.70)$ \\
\hline Day of admission to ICU & $7.19( \pm 3.75)$ \\
\hline \multicolumn{2}{|l|}{ COVID severity } \\
\hline - Moderate & • $13(40.6 \%)$ \\
\hline - Severe & • $19(59.4 \%)$ \\
\hline \multicolumn{2}{|l|}{ Comorbidity } \\
\hline - No & - $9(28.1 \%)$ \\
\hline - Yes & • $23(71.9 \%)$ \\
\hline - $\mathrm{HTN}$ & • $19(59.4 \%)$ \\
\hline - $\mathrm{DM}$ & • $7(21.9 \%)$ \\
\hline - IHD & - $4(12.5 \%)$ \\
\hline - $\mathrm{RA}$ & - $1(3.1 \%)$ \\
\hline - Koch's & • $1(3.1 \%)$ \\
\hline - Hypothyroid & - $1(3.1 \%)$ \\
\hline - $\mathrm{AF}$ (not on $\mathrm{OAC}$ ) & - $1(3.1 \%)$ \\
\hline SOFA score & $1.53( \pm 0.57)$ \\
\hline APACHE score & $15.16( \pm 3.48)$ \\
\hline \multicolumn{2}{|l|}{ IMV } \\
\hline - No & - $18(56.2 \%)$ \\
\hline - Yes & - $14(43.8 \%)$ \\
\hline
\end{tabular}

$\mathrm{OAC}$, oral anticoagulation; AF, atrial fibrillation; APACHE, Acute Physiology and Chronic Health Evaluation; COVID, coronavirus disease; DM, diabetes mellitus; HTN, hypertension; ICU, intensive care unit; IHD, ischemic heart disease; IMV, invasive mechanical ventilation; RA, rheumatoid arthritis; SOFA, Sequential Organ Failure Assessment

in comparison to an Indian study in non-COVID ICU patients, again more pronounced in severe forms of the disease.

The hypercoagulable nature of COVID-19 as evident from abnormal TEG ${ }^{12-19}$ and rotational thromboelastometry (ROTEM) ${ }^{20-22}$ findings have been reported recently. Hightower et al. observed the TEG profile of a small cohort of patients with COVID-19 and found that dysregulation of the fibrinolytic system is responsible for the hypercoagulable state. ${ }^{14}$ Maatman et al. analyzed TEG data of 12 patients admitted to ICU with severe COVID and found that $58 \%$ of them had a hypercoagulable state. ${ }^{15}$ Panigada et al. studied 24 patients and found a state of hypercoagulability as shown by decreased $R$ and $K$ values, and increased values of ANGLE and MA. ${ }^{16}$ Patel et al. observed 39 patients and found raised MA and absent fibrinolysis. ${ }^{17}$ Yuriditsky et al. studied 64 patients and found that $>50 \%$ of patients were hypercoagulable as reflected by different TEG parameters, and 31\% had VTE events. ${ }^{18}$ The mean LY-30 in our study is 2.77 and a complete lack is seen in only $12 / 32$ (37.5\%) patients hinting at a possibility of retained fibrinolytic function in the majority of patients, whereas Wright et al. (in 44 patients) found a very low $L Y 30$ of $0(0-0.4)$ [median (IQR)], a complete lack of LY30 in $57 \%$ of patients and also shown that fibrinolysis shutdown (elevated D-dimer and LY30 of 0) predicts VTE events. ${ }^{19}$ 
Table 2: Hematological and TEG parameters

\begin{tabular}{lc}
\hline Hematological parameters $($ NRR $)$ & Mean $( \pm$ SD $)$ \\
\hline Fibrinogen $(200-400 \mathrm{mg} / \mathrm{dL})$ & $558.02( \pm 198.77)$ \\
PT $(11-12.5 \mathrm{sec})$ & $12.10( \pm 1.83)$ \\
INR $(0.8-1.1)$ & $1.19( \pm 0.12)$ \\
aPTT $(30-40 \mathrm{sec})$ & $41.60( \pm 11.18)$ \\
Platelets $(1.5-4.0)$ & $2.10( \pm 0.88)$ \\
TEG parameter (manufacturer's reference range $)$ \\
TEG-R (3-8) & $4.15( \pm 1.56)$ \\
TEG-K (1-3) & $1.65( \pm 0.94)$ \\
TEG-ANGLE (55-78) & $66.03( \pm 10.17)$ \\
TEG-MA (51-69) & $67.39( \pm 13.75)$ \\
TEG-CI (-3 to 3) & $2.99( \pm 2.44)$ \\
TEG-LY30 (0-8) & $2.77( \pm 6.00)$ \\
\hline
\end{tabular}

ANGLE, alpha angle; aPTT, activated partial thromboplastin time; $\mathrm{Cl}$, coagulation index; INR, international normalized ratio; $\mathrm{K}$, kinetics; LY30, lysis at 30 min; MA, maximum amplitude; NRR, normal reference range; PT, prothrombin time; $R$, reaction time; TEG, thromboelastography

Table 3: TEG patterns

\begin{tabular}{|c|c|c|}
\hline TEG pattern & Criteria & Frequency/total (\%) \\
\hline Factor deficiency & $\begin{array}{l}\text { R time higher than } \\
\text { the upper limit of } \\
\text { NRR }\end{array}$ & $0 / 32(0)$ \\
\hline Low fibrinogen & $\begin{array}{l}\text { Normal R time and } \\
\text { MA, but ANGLE } \\
\text { below the lower limit } \\
\text { of NRR }\end{array}$ & $2 / 32(6.25 \%)$ \\
\hline Low platelet function & $\begin{array}{l}\text { Normal R time but } \\
\text { with an MA below } \\
\text { the lower limit of NRR }\end{array}$ & $3 / 32(9.38 \%)$ \\
\hline $\begin{array}{l}\text { Enzymatic hyperco- } \\
\text { agulability }\end{array}$ & $\begin{array}{l}\mathrm{Cl} \text { above the upper } \\
\text { limit of NRR with } \mathrm{R} \\
\text { time below the lower } \\
\text { limit of NRR and } \\
\text { normal MA }\end{array}$ & $1 / 32(3.13 \%)$ \\
\hline $\begin{array}{l}\text { Combined enzymatic } \\
\text { and platelet hyperco- } \\
\text { agulability }\end{array}$ & $\begin{array}{l}\mathrm{Cl} \text { above the upper } \\
\text { limit of NRR with R } \\
\text { time below the lower } \\
\text { limit of NRR and } \\
\text { having an MA higher } \\
\text { than the upper limit } \\
\text { of NRR }\end{array}$ & $7 / 32(21.88 \%)$ \\
\hline Primary fibrinolysis & $\begin{array}{l}\text { LY30 higher than the } \\
\text { upper limit of normal } \\
\text { reference range with } \\
\text { Cl below the lower } \\
\text { limit of NRR }\end{array}$ & $0 / 32(0)$ \\
\hline $\begin{array}{l}\text { Secondary fibrinoly- } \\
\text { sis }\end{array}$ & $\begin{array}{l}\mathrm{LY} 30 \text { and } \mathrm{Cl} \text { higher } \\
\text { than the upper limit } \\
\text { of NRR }\end{array}$ & $1 / 32(3.13 \%)$ \\
\hline
\end{tabular}

ANGLE, alpha angle; $\mathrm{Cl}$, coagulation index; $\mathrm{K}$, kinetics; $\mathrm{LY} 30$, lysis at $30 \mathrm{~min}$; $M A$, maximum amplitude; NRR, normal reference range; $R$, reaction time; TEG, thromboelastography

Various studies and recent reviews have pointed out that there is a high incidence of VTE events in ICU patients with COVID-19 and that these events are occurring on the background of standard thromboprophylaxis. ${ }^{5}$ Our study also has shown hypercoagulability
Table 4: Coagulation status based on TEG-CI

\begin{tabular}{ll}
\hline Coagulation status & Frequency/total (\%) \\
\hline Hypocoagulable $(\mathrm{Cl}<-3)$ & $0 / 32(0)$ \\
Normocoagulable $(\mathrm{Cl}-3$ to 3$)$ & $12 / 32(37.5 \%)$ \\
Hypercoagulable $(\mathrm{Cl}>3)$ & $20 / 32(62.5 \%)$ \\
\hline
\end{tabular}

$\mathrm{Cl}$, coagulation index; TEG, thromboelastography

despite giving standard doses of enoxaparin. Few studies have also studied the duration of altered coagulation state and linked the hypercoagulability to the occurrence of VTE events and the worse prognosis of the disease. ${ }^{6,22}$ Thromboelastography can be an easy and helpful test to learn about this new disease and may have potential in deciding appropriate anticoagulant doses and duration. ${ }^{7,23,24}$ Some experts advise TEG in patients with severe COVID-19 for monitoring coagulation and adjusting the heparin dosage. ${ }^{25}$ More studies are needed to evaluate the applicability of TEG in understanding the disease, identifying appropriate doses and duration of thromboprophylaxis, and predicting outcomes.

\section{Limitations}

The retrospective and a small number of patients in our study can limit the generalization and applicability of the results. Sequential TEG was not done, which could give more understanding of evolving patterns through the course of the disease. The correlation was not done with VTE or bleeding events.

\section{Conclusion}

To our knowledge, this is the first Indian study to characterize coagulation profiles based on TEG in patients with COVID-19 admitted to ICU. Hypercoagulability is observed in the majority of the patients which is more pronounced in severe forms of the disease. Fibrinolysis is also retained in the majority of patients which is a positive sign.

\section{Contribution of Authors}

All the authors are involved in design, analysis, interpretation, critical review and final approval, and agree to be accountable for all aspects of the work in ensuring that questions related to the accuracy or integrity of any part of the work are appropriately investigated and resolved.

\section{HighLights}

- Hypercoagulation on thromboelastography (high TEG-Cl) found in $62.5 \%$ of the patients with COVID-19 admitted to ICU.

- Hypercoagulability found in other TEG parameters also and is more pronounced in severe forms of the disease.

- TEG-LY30 is within normal range indicating a good fibrinolysis function.

- The potential of TEG in identifying appropriate doses and duration of thromboprophylaxis and predicting outcomes need to be evaluated.

\section{References}

1. WHO. Coronavirus disease COVID-2019 Situational report-161. WHO Publication; 2020.

2. Gustafson D, Raju S, Wu R, Ching C, Veitch S, Rathnakumar K, et al. Overcoming barriers: the endothelium as a linchpin of coronavirus 
disease 2019 pathogenesis? Arterioscler Thromb Vasc Biol [Internet] 2020;40(8):1818-1829. DOI: 10.1161/ATVBAHA.120.314558Available from: https://pubmed.ncbi.nlm.nih.gov/32510978.

3. Chan NC, Weitz JI. COVID-19 coagulopathy, thrombosis, and bleeding. Blood [Internet] 2020;136(4):381-383. DOI: 10.1182/ blood.2020007335.

4. Richardson S, Hirsch JS, Narasimhan M, Crawford JM, McGinn T, Davidson KW, et al. Presenting characteristics, comorbidities, and outcomes among 5700 patients hospitalized with COVID-19 in the New York city area. JAMA [Internet] 2020;323(20):2052-2059. DOI: 10.1001/jama.2020.6775.

5. Al-Ani F, Chehade S, Lazo-Langner A. Thrombosis risk associated with COVID-19 infection. A scoping review. Thromb Res 2020. DOI: 10.1016/j.thromres.2020.05.039.

6. Al-Samkari H, Karp Leaf RS, Dzik WH, Carlson JCT, Fogerty AE, Waheed $A$, et al. COVID and coagulation: bleeding and thrombotic manifestations of SARS-CoV2 infection. Blood 2020(4). DOI: 10.1182/ blood.2020006520.

7. Harahsheh Y, Ho KM. Use of viscoelastic tests to predict clinical thromboembolic events: a systematic review and meta-analysis. Eur J Haematol [Internet] 2018;100(2):113-123. DOI: 10.1111/ejh.12992.

8. Ranieri VM, Rubenfeld GD, Thompson BT, Ferguson ND, Caldwell $E$, Fan E, et al. Acute respiratory distress syndrome: the Berlin definition. JAMA [Internet] 2012;307(23):2526-2533. DOI: 10.1001/ jama.2012.5669.

9. Mohfw.gov.in. Revised Guidelines on Clinical Management of COVID - 19. Mohfw. 2020.

10. Subramanian A, Albert V, Saxena R, Agrawal D, Pandey RM. Establishing a normal reference range for thromboelastography in North Indian healthy volunteers. Indian J Pathol Microbiol 2014;57(1):43-50. DOI: 10.4103/0377-4929.130896.

11. Ahammad J, Kurien A, Shastry S, Shah HH, Nayak D, Kamath A, et al. Age-and gender-related reference ranges for thromboelastography from a healthy Indian population. Int J Lab Hematol [Internet] 2020;42(2):180-189. DOI: 10.1111/ijlh.13148.

12. Lorenzo C, Francesca B, Francesco P, Elena C, Luca S, Paolo S. Acute pulmonary embolism in COVID-19 related hypercoagulability. J Thromb Thrombolysis 2020(1):1-4. DOI: 10.1007/s11239-020-02160-1.

13. Raval JS, Burnett AE, Rollins-Raval MA, Griggs JR, Rosenbaum L, Nielsen ND, et al. Viscoelastic testing in COVID-19: a possible screening tool for severe disease? Transfusion 2020;60(6):1131-1132. DOI: 10.1111/trf.15847.

14. Hightower S, Ellis H, Collen J, Ellis J, Grassol, Roswarski J, et al. Correlation of indirect markers of hypercoagulability with thromboelastography in severe coronavirus 2019. Thromb Res [Internet] 2020;195:69-71. DOI: 10.1016/j.thromres.2020.07.013Available from: https://pubmed. ncbi.nlm.nih.gov/32659463.

15. Maatman TK, Jalali F, Feizpour C, Douglas All, McGuire SP, Kinnaman G, et al., Routine Venous Thromboembolism Prophylaxis May Be Inadequate in the Hypercoagulable State of Severe
Coronavirus Disease 2019. Crit Care Med [Internet]. 9000;Online Fir. Available from: https://journals.Iww.com/ccmjournal/Fulltext/9000/ Routine_Venous_Thromboembolism_Prophylaxis_May_Be.95638. aspx.

16. Panigada M, Bottino N, Tagliabue P, Grasselli G, Novembrino C, Chantarangkul V, et al. Hypercoagulability of COVID-19 patients in intensive care unit. A report of thromboelastography findings and other parameters of Hemostasis. J Thromb Haemost 2020;18(7):17381742. DOI: 10.1111/jth.14850.

17. Patel BV, Arachchillage DJ, Ridge CA, Bianchi P, Doyle JF, Garfield B, et al. Pulmonary angiopathy in severe COVID-19: Physiologic, imaging and Hematologic observations. Am J Respir Crit Care Med [Internet] 2020(5). DOI: 10.1164/rccm.202004-14120C.

18. Yuriditsky E, Horowitz JM, Merchan C, Ahuja T, Brosnahan SB, McVoy $\mathrm{L}$, et al. Thromboelastography profiles of critically ill patients with coronavirus disease 2019. Crit Care Med [Internet] 2020. DOI: 10.1097/ CCM.0000000000004471Available from: https://pubmed.ncbi.nlm. nih.gov/32618696.

19. Wright FL, Vogler TO, Moore EE, Moore HB, Wohlauer MV, Urban S, et al. Fibrinolysis shutdown correlation with thromboembolic events in severe COVID-19 infection. J Am Coll Surg [Internet] 2020;231(2):193203.e1. DOI: 10.1016/j.jamcollsurg.2020.05.007.

20. Ibañez C, Perdomo J, Calvo A, Ferrando C, Reverter JC, Tassies D, et al. High D dimers and low global fibrinolysis coexist in COVID19 patients: what is going on in there? J Thromb Thrombolysis [Internet] 2020. 1-5. DOI: 10.1007/s11239-020-02226-0.

21. Spiezia L, Boscolo A, Poletto F, Cerruti L, Tiberio I, Campello E, et al. COVID-19-related severe hypercoagulability in patients admitted to intensive care unit for acute respiratory failure. Thromb Haemost 2020;120(6):998-1000. DOI: 10.1055/s-0040-1710018.

22. Pavoni V, Gianesello L, Pazzi M, Stera C, Meconi T, Frigieri FC. Evaluation of coagulation function by rotation thromboelastometry in critically ill patients with severe COVID-19 pneumonia. J Thromb Thrombolysis [Internet] 2020;50(2):281-286. DOI: 10.1007/s11239020-02130-7.

23. Poddar B, Verma A, Gurjar M, Baronia AK, Singh RK, Muzaffar SN, et al. Thromboelastography for evaluation of coagulopathy in nonbleeding patients with sepsis at intensive care unit admission. Indian J Crit Care Med 2017;21(5):268-273. DOI: 10.4103/ijccm. IJCCM_72_17.

24. Rubulotta F, Soliman-Aboumarie H, Filbey K, Geldner G, Kuck K, Ganau M, et al. Technologies to optimize the care of severe COVID-19 patients for health care providers challenged by limited resources. Anesth Analg [Internet] 2020;131(2):Available from: https://journals. Iww.com/anesthesia-analgesia/Fulltext/2020/08000/Technologies_ to_Optimize_the_Care_of_Severe.8.aspx.

25. Song J-C, Wang G, Zhang W, Zhang Y, Li W-Q, Zhou Z, et al. Chinese expert consensus on diagnosis and treatment of coagulation dysfunction in COVID-19. Mil Med Res [Internet] 2020;7(1):19. DOI: 10.1186/s40779-020-00247-7. 
TEG in COVID-19

\begin{tabular}{|c|c|c|c|c|c|c|c|c|c|}
\hline & & \multicolumn{8}{|c|}{ Correlations } \\
\hline & & SOFA & APACHE & TEGR & TEGK & TEGANGLE & TEGMA & TEGCI & TEGLY30 \\
\hline \multirow[t]{3}{*}{ SOFA } & $\begin{array}{l}\text { Pearson } \\
\text { correlation }\end{array}$ & 1 & $0.708^{* *}$ & -0.091 & -0.115 & 0.135 & $0.413^{*}$ & 0.214 & -0.040 \\
\hline & Sig. (two-tailed) & & 0.000 & 0.620 & 0.530 & 0.461 & 0.019 & 0.239 & 0.832 \\
\hline & $N$ & 32 & 32 & 32 & 32 & 32 & 32 & 32 & 30 \\
\hline \multirow[t]{3}{*}{ APACHE } & $\begin{array}{l}\text { Pearson } \\
\text { correlation }\end{array}$ & $0.708^{* *}$ & 1 & -0.104 & 0.020 & 0.008 & 0.168 & 0.039 & -0.167 \\
\hline & Sig. (two-tailed) & 0.000 & & 0.571 & 0.912 & 0.965 & 0.359 & 0.833 & 0.379 \\
\hline & $N$ & 32 & 32 & 32 & 32 & 32 & 32 & 32 & 30 \\
\hline \multirow[t]{3}{*}{ TEGR } & $\begin{array}{l}\text { Pearson } \\
\text { correlation }\end{array}$ & -0.091 & -0.104 & 1 & $0.510^{* *}$ & $-0.388^{*}$ & $-0.552^{* *}$ & $-0.659^{* *}$ & 0.127 \\
\hline & Sig. (two-tailed) & 0.620 & 0.571 & & 0.003 & 0.028 & 0.001 & 0.000 & 0.505 \\
\hline & $N$ & 32 & 32 & 32 & 32 & 32 & 32 & 32 & 30 \\
\hline \multirow[t]{3}{*}{ TEGK } & $\begin{array}{l}\text { Pearson } \\
\text { correlation }\end{array}$ & -0.115 & 0.020 & $0.510^{* *}$ & 1 & $-0.524^{* *}$ & $-0.672^{* *}$ & $-0.405^{*}$ & -0.073 \\
\hline & Sig. (two-tailed) & 0.530 & 0.912 & 0.003 & & 0.002 & 0.000 & 0.022 & 0.701 \\
\hline & $N$ & 32 & 32 & 32 & 32 & 32 & 32 & 32 & 30 \\
\hline \multirow[t]{3}{*}{ TEGANGLE } & $\begin{array}{l}\text { Pearson } \\
\text { correlation }\end{array}$ & 0.135 & 0.008 & $-0.388^{*}$ & $-0.524^{* *}$ & 1 & 0.268 & $0.634^{* *}$ & -0.110 \\
\hline & Sig. (two-tailed) & 0.461 & 0.965 & 0.028 & 0.002 & & 0.138 & 0.000 & 0.564 \\
\hline & $N$ & 32 & 32 & 32 & 32 & 32 & 32 & 32 & 30 \\
\hline \multirow[t]{3}{*}{ TEGMA } & $\begin{array}{l}\text { Pearson } \\
\text { correlation }\end{array}$ & $0.413^{*}$ & 0.168 & $-0.552^{* *}$ & $-0.672^{* *}$ & 0.268 & 1 & $0.454^{* *}$ & 0.032 \\
\hline & Sig. (two-tailed) & 0.019 & 0.359 & 0.001 & 0.000 & 0.138 & & 0.009 & 0.865 \\
\hline & $N$ & 32 & 32 & 32 & 32 & 32 & 32 & 32 & 30 \\
\hline \multirow[t]{3}{*}{ TEGCI } & $\begin{array}{l}\text { Pearson } \\
\text { correlation }\end{array}$ & 0.214 & 0.039 & $-0.659^{* *}$ & $-0.405^{*}$ & $0.634^{* *}$ & $0.454^{* *}$ & 1 & -0.195 \\
\hline & Sig. (two-tailed) & 0.239 & 0.833 & 0.000 & 0.022 & 0.000 & 0.009 & & 0.303 \\
\hline & $N$ & 32 & 32 & 32 & 32 & 32 & 32 & 32 & 30 \\
\hline \multirow[t]{3}{*}{ TEGLY30 } & $\begin{array}{l}\text { Pearson } \\
\text { correlation }\end{array}$ & -0.040 & -0.167 & 0.127 & -0.073 & -0.110 & 0.032 & -0.195 & 1 \\
\hline & Sig. (two-tailed) & 0.832 & 0.379 & 0.505 & 0.701 & 0.564 & 0.865 & 0.303 & \\
\hline & $N$ & 30 & 30 & 30 & 30 & 30 & 30 & 30 & 30 \\
\hline
\end{tabular}

${ }^{*}$ Correlation is significant at the 0.05 level (two-tailed)

${ }^{* *}$ Correlation is significant at the 0.01 level (two-tailed) 